\title{
Perfil das crianças de 0 a 6 anos que freqüentam creches, pré-escolas e escolas: uma análise dos resultados da Pesquisa sobre Padrões de Vida/IBGE
}

\section{Maria Dolores Bombardelli Kappel}

Instituto Brasileiro de Geografia e Estatística. D outoranda em Educação na PU C-Rio

\section{Maria Cristina Carvalho}

Mestranda em Educação na PUC-Rio

\section{Sonia Kramer}

PUC-Rio, D epartamento de Educação

\section{Introdução}

Este trabalho é parte de um estudo realizado com os objetivos de revisar conceitos relativos à educação da criança de 0 a 6 anos, com base na bibliografia produzida no Brasil nos últimos 20 anos e analisar, à luz da revisão feita e no que se refere aos dados relativos às crianças de 0 a 6 anos, a Pesquisa sobre Padrões de Vida (PPV) realizada pelo IBGE em 1996 e 1997. O estudo foi viabilizado pela parceria da PUC-Rio com o IBGE, que disponibilizou os dados e garantiu a constituição de uma equipe formada por educadores e estatísticos.

O estudo analisou concepções de infância e de educação infantil e apresentou uma síntese da história e das políticas de educação infantil no Brasil, seu papel e importância. Fez também considerações sobre a educação infantil na nova Lei de Diretrizes e Bases da Educação Nacional e retomou, ainda numa perspectiva histórica, dados estatísticos disponíveis relativos à educação da criança de 0 a 6 anos, para então focalizar e discutir os dados da Pesquisa sobre Padrões de Vida/PPV, realizada pelo IBGE, específicos à educação da criança de 0 a 6 anos, tema do presente trabalho.
O presente texto está estruturado da seguinte maneira: inicialmente apresenta aspectos conceituais e uma breve discussão sobre dados estatísticos no campo da educação infantil; em seguida, situa a pesquisa em que se baseia este estudo, identifica quem são as crianças de 0 a 6 anos que freqüentam creches, pré-escolas e escolas e que fatores influenciam esta freqüência.

\section{Infância e educação da criança de 0 a 6 anos: questões conceituais}

Creche e pré-escola são, em geral, diferenciadas ora pela idade das crianças incluídas nos programas - a creche se definiria por incluir crianças de 0 a 3 anos e a pré-escola de 4 a $6^{1}$-, ora pelo seu tipo de funcionamento e pela sua extensão em termos sociais - a creche se caracterizaria por uma atuação em "horário integral", e a pré-escola por um funcionamento semelhante ao da escola, em "meio período" ou turno. Há ainda uma terceira classificação que diz respeito à vinculação administrati-

${ }^{1}$ Esta é a definição adotada pela Constituição Federal e pela Lei de Diretrizes e Bases da Educação Nacional. 
va: a creche se subordinaria a órgãos de caráter médico ou assistencial, e a pré-escola ao sistema educacional. Hoje, no Brasil, diferentes instituições referem-se à creche ou pré-escola utilizando um ou outro critério, de modo que esta é ainda uma denominação pouco uniforme tanto para órgãos que atuam na área, quanto para a população em geral. A partir de meados dos anos 80, o movimento desencadeado em defesa das populações infantis, com vista à Assembléia Nacional Constituinte e, mais tarde, à nova Lei de Diretrizes e Bases da Educação Nacional, pretendeu consolidar a expressão "educação da criança de 0 a 6 anos" ou "educação infantil" para designar o trabalho realizado em creches e pré-escolas. ${ }^{2}$

A creche e a pré-escola representam alternativas concretas para viabilizar a liberação da mulher para o mercado de trabalho, mas em todos os tipos de atendimento se coloca como igualmente relevante a necessidade de que o trabalho realizado no seu interior tenha não só um caráter assistencial, mas principalmente educativo. Assim, além da garantia do atendimento nutricional, de saúde e de segurança, se reconhece a importância de existirem condições de funcionamento e de recursos materiais e humanos que propiciem benefícios sociais e culturais para as crianças. Em que pese as ambigüidades das diversas categorizações, a questão educacional está, portanto, nelas presente, entendendose pré-escola como trabalho com crianças de 4 a 6 anos, de meio período ou horário integral, inserida ou não no espaço da creche, cuja responsabilidade é ou deveria ser assumida pela instância educacional pública. Nesse sentido, creches e pré-escolas são instituições de educação infantil a que todas as crianças de 0 a 6 anos têm direito.

\section{A educação infantil nosdados estatísticos- uma retrospectiva}

Diversas são as fontes de dados disponíveis ${ }^{3}$ e as possíveis análises sobre a educação da criança de 0 a 6

${ }^{2}$ A expressão "educação infantil” foi cunhada a partir das discussões na Assembléia Constituinte de 1987/1988 e da Lei de Diretrizes e Bases da Educação. Ver, entre outros, Campos (1986) e Kramer (1988 e 1992)

${ }^{3}$ Pesquisa Nacional por Amostra de Domicílios/ IBGE e Censo Escolar/MEC anos, embora fontes e pesquisas tenham sido muitas vezes alvo de controvérsia. Entretanto, no que diz respeito à infância, o mais grave é a realidade que os dados revelam. De acordo com o Diagnóstico Preliminar da Educação Pré-Escolar no Brasil - primeiro levantamento de dados realizado pelo MEC, em 1975 - a população de 0 a 6 anos oscilava naquele momento em torno de 21 milhões. Segundo referências daquele Diagnóstico, apenas $3,51 \%$ eram atendidas, sendo $44 \%$ das matrículas em creches e pré-escolas particulares.

De modo geral, as estatísticas sobre educação infantil são relativamente recentes nos países da América Latina. No Brasil, só passaram a figurar no Anuário Estatístico em 1974. O motivo principal residia na suposição de que a verdadeira educação começava na primeira série do primeiro grau, situação que, felizmente, vem se modificando. Os pressupostos teóricos que contribuíram para a mudança de atitude na política de Educação Infantil no Brasil são explicitados por diversos autores. Neste contexto, Ferrari \& Gaspary (1980), com base nas teorias e pressupostos que nortearam tais políticas, analisam dados estatísticos relativos à distribuição de oportunidades de educação pré-escolar no Brasil, a partir de uma visão da educação infantil concebida como pré-requisito para um desempenho ótimo da criança na sua fase de escolarização regular.

No entanto, além da reflexão sobre a dimensão ideológica subjacente à questão da infância, cabe observar atentamente a evolução da educação pré-escolar no Brasil através da análise das matrículas, dos índices de atendimento e da participação do setor público - União, estados e municípios - e do setor privado nessa evolução. Incluindo a população de 0 a 6 anos, a distribuição e evolução, no período de 1979 a 1991, é mostrada no Quadro 1.

Percebe-se, pois, que o índice de escolarização na faixa de 0 a 6 anos aumentou de 5,5\% em 1979 para $15,5 \%$ em 1991. Índice ainda muito baixo, mas que representou 2,81 vezes o índice de 1979, portanto, um aumento significativo.

Trabalhos mais recentes ${ }^{4}$ vêm sendo realizados tanto na linha de levantamentos, diagnósticos ou estudos

\footnotetext{
${ }^{4}$ Rosemberg (1999) e Campos (1997).
} 
censitários e seus resultados lançam alguma luz sobre a evolução do atendimento às crianças de 0 a 6 anos. É fundamental observar tais dados, ainda que seja muitas vezes complicado compará-los.

\section{Quadro 1}

Evolução da população de 0 a 6 anos de idade e das matrículas no pré-escolar e percentual de crianças atendidas no pré-escolar - Brasil, 1979/1991

\begin{tabular}{|c|c|c|c|}
\hline Ano & $\begin{array}{c}\text { População } \\
\text { de 0 a 6 anos }\end{array}$ & $\begin{array}{c}\text { Matrícula no } \\
\text { Pré-escolar }\end{array}$ & $\begin{array}{c}\text { Percentual de crianças } \\
\text { atendidas (\%) }\end{array}$ \\
\hline 1979 & 21.607 .168 & 1.198 .104 & 5,5 \\
\hline 1980 & 22.536 .396 & 1.335 .317 & 5,9 \\
\hline 1981 & 21.994 .879 & 1.543 .822 & 7,0 \\
\hline 1982 & 22.830 .755 & 1.866 .868 & 8,2 \\
\hline 1983 & 23.266 .679 & 2.084 .109 & 9,0 \\
\hline 1984 & 23.334 .177 & 2.481 .848 & 10,6 \\
\hline $1985(1)$ & 23.618 .510 & 2.524 .000 & 10,7 \\
\hline 1986 & 23.759 .776 & 3.083 .997 & 13,0 \\
\hline 1987 & 23.805 .397 & 3.296 .010 & 13,8 \\
\hline 1988 & 23.407 .707 & 3.375 .834 & 14,4 \\
\hline 1989 & 23.133 .083 & 3.396 .074 & 14,7 \\
\hline 1991 & 23.391 .541 & 3.628 .285 & 15,5 \\
\hline
\end{tabular}

Fontes: IBGE. Censo Demográfico 1980 e 1991e MEC/SEEC. Censo Escolar. (1) Dados estimados.

Mesmo conscientes de que os dados não são "dados" mas construídos, não podemos fechar os olhos a algumas pistas sobre a realidade que descortinam: os números delineiam uma situação onde grande parte das crianças de 0 a 6 anos não recebem ainda educação, mas, ao mesmo tempo, apontam o real processo gradativo de democratização da educação infantil.

Utilizando-se de dados coletados pela PNAD (Pesquisa Nacional sob Amostra Domiciliar) no ano de 1996, o IBGE apresenta tabela das crianças de 0 a 6 anos que freqüentam a creche e/ou pré-escola segundo as Grandes Regiões e Unidades da Federação.

Contudo, fazendo uma inflexão, vale mencionar que no contexto do problema da distorção idade/série enfrentado no nosso sistema educacional, a área da Edu- cação Infantil apresenta uma peculiaridade: é elevado o número de crianças da faixa etária de 7 e 8 anos que freqüentam classes de pré-escola, quando já deveriam estar nas primeiras séries da escola fundamental. Embora possa parecer que este aspecto extrapola o âmbito do presente estudo, voltado à caracterização das crianças de 0 a 6 anos, é importante lembrar que, no Brasil, de acordo com os resultados da PNAD 1997, 858.554 vagas em instituições de educação infantil são ocupadas por crianças de 7 e 8 anos.

\section{Quadro 2}

População de 0 a 6 anos, por grupos de idade e freqüência à creche ou pré-escola, segundo as Grandes Regiões - 1996

\begin{tabular}{|c|c|c|c|}
\hline Grandes regiões & População de 0 & $\begin{array}{c}\text { Proporção de crianças freqüentando } \\
\text { a 6 anos de idade }\end{array}$ & $\begin{array}{r}\mid c \\
\text { creche ou pré-escola (\%) }\end{array}$ \\
\cline { 3 - 4 } & & De 0 a 3 anos & De 4 a 6 anos \\
\hline Brasil (1) & 20.870 .125 & 7,43 & 48,22 \\
\hline Norte (2) & 1.226 .151 & 5,89 & 44,41 \\
\hline Nordeste & 7.041 .023 & 6,75 & 50,51 \\
\hline Sudeste & 8.050 .352 & 8,50 & 52,34 \\
\hline Sul & 3.059 .716 & 8,23 & 38,49 \\
\hline Centro-oeste & 1.492 .883 & 4,72 & 38,96 \\
\hline
\end{tabular}

Fonte: IBGE, Pesquisa Nacional por Amostra de Domicílios 1996, microdados.

(1) Exclusive a população rural de Rondônia, Acre, Amazonas, Roraima, Pará, Amapá e Tocantins. (2) Exclusive a população da zona rural.

Entretanto, os estudos sobre o impacto da educação pré-escolar - questão importante que mobilizou mundialmente a área acadêmica e que se configurou como crucial no que se refere às decisões governamentais nos anos 80 - mostram-se desde aquela época bastante polêmicos. Neste sentido, a pesquisa de Pozner (1982), relativa a estudo feito na Argentina como parte da investigação também desenvolvida no Chile, Bolívia e Colômbia, com o objetivo de detectar se as crianças dos setores populares se beneficiavam com a educação pré-escolar em sua educação primária posterior, afirmava que o "pré-escolar influi consideravelmente na promoção das crianças na primeira série", alertando porém para o fato de que "eram as crianças de níveis alto e 
médio as mais beneficiadas" dados indicassem que o pré-escolar interferia na vida escolar futura das crianças, esta influência se mostrava fortemente associada ao nível socioeconômico da família ou à área geográfica.

Em trabalho recente, Campos (1997) apresenta um resumo dos principais resultados obtidos por um grupo de pesquisas significativas, realizadas na Grã-Bretanha, nos Estados Unidos e na América Latina, que procuraram avaliar os efeitos da freqüência a programas de educação infantil sobre o desenvolvimento e a escolaridade posterior de crianças de diversas origens sociais, étnicas e culturais. Destaca alguns dos principais achados destas pesquisas tais como: a frequiência à pré-escola favorece os resultados que as crianças obtêm em testes realizados no início da escolaridade; as crianças mais pobres parecem se beneficiar mais dessa experiência; a importância da qualidade da pré-escola e também da própria escola elementar na conservação desse benefício. Ressalta que as pesquisas sobre o impacto das creches são em número muito menor do que aquelas sobre pré-escola.

Há que se notar como após 15 anos - período que separa os textos de Pozner (1982) e Campos (1997) -, e graças ao avanço teórico-metodológico conquistado neste período, os resultados dos estudos comentados por Campos são mais abrangentes do que os encontrados por Pozner. Hoje há, portanto, informações disponíveis a respeito do impacto positivo da freqüência a creches e pré-escolas sobre o desempenho na escola. Lamentavelmente, as diretrizes que nortearam a educação da criança naquele período basearam-se em dados que se mostraram ultrapassados. Do nosso ponto de vista, a questão se situava (e se situa ainda) mais na dimensão política do que em evidências estatísticas: trata-se do direito de todas as crianças de 0 a 6 anos à educação infantil, preceito constitucional, fruto de muitas lutas da sociedade civil no Brasil, no decorrer dos anos 80 e 90 .

\footnotetext{
${ }^{5}$ Texto original em espanhol; tradução feita pelas autoras.
}

\section{Situando a pesquisa em que se baseia este estudo}

Como foi apresentado no item anterior, estão hoje disponíveis dados quantitativos e levantamentos relativos ao número de crianças de 0 a 6 anos que freqüentavam ou freqüentam pré-escola e creche. Entretanto, não há dados mais abrangentes referentes às crianças que contenham informações - onde e como vivem, quem são seus pais, o que fazem, como é sua escola, pré-escola ou creche - que possibilitariam um maior conhecimento da situação da criança de 0 a 6 anos. A sistematização de tais dados favoreceria o delineamento de caminhos mais nítidos nesta área, tanto em termos de políticas de expansão quanto de estabelecimento de prioridades e definição de estratégias de ação.

A Pesquisa sobre Padrões de Vida, realizada em 1996 e 1997 pelo IBGE, objetiva preencher essa lacuna, trazendo um conjunto de informações que foram obtidas a partir da coleta de dados sobre 16 diferentes temáticas.

No presente estudo, pretende-se conhecer o perfil da criança de 0 a 6 anos que freqüenta instituições de educação infantil, bem como avaliar a qualidade desta e os fatores que influenciam na frequiência. Além disso, pretende-se também verificar, com base no histórico escolar das pessoas nascidas nas décadas de 1970 e 1980, como estão relacionados freqüência à creche ou à préescola e escolaridade posterior. Vale esclarecer que a PPV se refere a "estabelecimentos de ensino" para falar de educação de crianças de 0 a 6 anos. Optou-se, porém, por usar "escola, pré-escola ou creche" e, de modo geral, "estabelecimentos de educação", considerandose que $11,0 \%$ das crianças que freqüentavam "estabelecimentos de ensino" estavam matriculadas na escola fundamental.

É importante explicitar aqui as condições de realização da pesquisa. Os dados da PPV foram coletados em 4800 domicílios das regiões Nordeste e Sudeste, considerando-se 10 estratos geográficos: Região Metropolitana de Fortaleza, Região Metropolitana de Recife, Região Metropolitana de Salvador, restante do Nordeste urbano, restante do Nordeste rural, Região Metropolitana de Belo Horizonte, Região Metropolitana do Rio de Janeiro, Região Metropolitana de São Paulo, restan- 
te do Sudeste urbano e restante do Sudeste rural. A amostra foi selecionada a partir de um desenho concebido em dois estágios. Foram escolhidos 480 domicílios por estrato geográfico, distribuídos em 60 setores com 8 domicílios cada um, exceto no restante rural, onde foram amostrados 30 setores com 16 domicílios cada um. Cada domicílio da amostra representou um certo número de domicílios na população pesquisada. Este número foi o fator de expansão ou peso do domicílio que, associado às características investigadas na pesquisa, permitiu a obtenção de estimativas para o universo do qual a amostra foi selecionada. Sendo assim, todas as análises estatísticas utilizaram pesos nas estimativas.

Para verificar o efeito que a freqüência à creche ou pré-escola exercia na escolaridade dos indivíduos nascidos nas décadas de 1970 e 1980 foi tomada como ponto de partida a seção 2-A da PPV, que descreve os moradores entrevistados. Nesta, foram selecionados os indivíduos nascidos entre 1970 e 1989; criou-se então um identificador para cada um deles, considerando o seu domicílio e o seu número de ordem no domicílio. A partir daí, foram acrescidas as variáveis selecionadas do Histórico Escolar (seção 4-B), que permitiam constatar se as pessoas tinham freqüentado creche ou pré-escola.

Para conhecer o perfil das crianças de 0 a 6 anos matriculadas em instituições educativas foi também tomada como ponto de partida a seção 2-A, que descreve os moradores. Nesta, foram selecionados os indivíduos com idade entre 0 e 6 anos; criou-se então um identificador para cada um deles, considerando o seu domicílio e o seu número de ordem. A partir daí, foram acrescidas as variáveis selecionadas nas seções 1 - Características do domicílio, 4 - Educação e 6 - Atividades econômicas. As características geográficas foram obtidas a partir do arquivo Estrat e a renda domiciliar, a partir do arquivo Rendadom.

\section{Crianças de 0 a 6 anosque freqüentam creche/pré-escola/escola - quem são?}

As crianças matriculadas em creches, pré-escolas ou escolas encontram-se igualmente distribuídas entre as regiões Nordeste $(46,7 \%)$ e Sudeste $(53,3 \%)$. Porém, esta distribuição igualitária não é observada em termos de área urbana e rural: a grande maioria $(82,2 \%)$ destas crianças está localizada nas cidades. Apesar desta concentração, 88,0\% delas moram em casas, enquanto apenas $10,9 \%$ moram em apartamentos. Além disso, 79,6\% vivem em construções isoladas, enquanto $13,8 \%$ vivem em condomínios regularizados. Destes domicílios, 65,8\% são próprios, $16,0 \%$ são alugados e $17,1 \%$ são cedidos. Em relação às condições de saneamento, a grande maioria das crianças mora em domicílios com água encanada $(79,2 \%)$ e luz elétrica $(94,4 \%)$. Entretanto, somente $52,1 \%$ dos domicílios possuem rede coletora de esgoto. Como a amostra foi realizada levando-se em consideração a renda, a distribuição das crianças por quintos de renda, como era de se esperar, foi igualitária, com porcentagens em torno dos $20 \%$.

As crianças de 0 a 6 anos que vão à creche, préescola ou escola moram junto com até quinze pessoas, sendo que em $82,3 \%$ destes domicílios moram de três a seis pessoas. Em sua grande maioria $(87,6 \%)$, as crianças são filhas do chefe da casa, mas podem ser outros parentes $(12,2 \%)$ ou agregados $(0,2 \%)$ da família. Metade $(48,9 \%)$ é constituída por homens, metade $(51,1 \%)$ por mulheres. Em convergência com o que aponta Rosemberg (1991 e 1996), o número de crianças brancas é superior $(57,7 \%)$ ao de crianças pretas/pardas $(42,3 \%)$.

\section{Gráfico 1}

Distribuição de crianças de 0 a 6 anos de idade que freqüentam estabelecimentos de educação, por idade pontual - período março 1996/março 1997

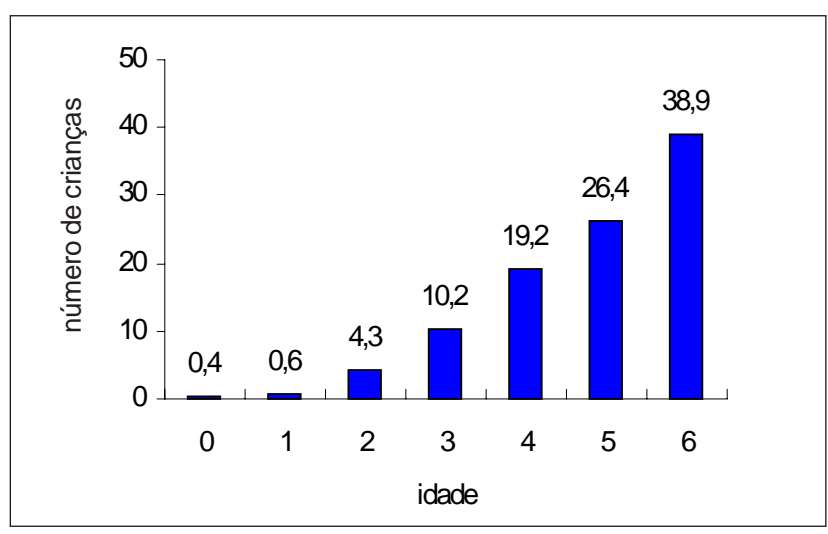

Fonte: Pesquisa sobre padrões de vida 1996-1997 [CD-ROM]. Microdados. Rio de Janeiro: IBGE, 1998. 
Percentagem significativa $(8,3 \%)$ dessas crianças é alfabetizada: lê jornais, escreve cartas e faz contas por escrito. Além disso, como se observa no Gráfico 1, a matrícula aumenta com a idade: o número de crianças de 6 anos matriculadas é 88 vezes maior do que o número de bebês com apenas alguns meses que freqüentam a creche.

Portanto, como pode ser observado no gráfico, $40 \%$ das crianças de 0 a 6 anos que freqüentam escolas, creches ou pré-escolas têm 6 anos, enquanto apenas 15\% das crianças atendidas têm de 0 a 3 anos.

No que diz respeito às famílias das crianças, em $82,0 \%$ dos casos o pai mora no domicílio; em $96,6 \%$ dos casos, a mãe mora no domicílio. A partir do que os dados sugerem, são crianças que têm, portanto, família estruturada em torno de um chefe de família.

Dos pais dessas crianças, 35,9\% concluíram os quatro primeiros anos de escolaridade, sendo que $17,4 \%$ não têm escolaridade e 12,1\% têm curso superior completo. Das mães, $36,3 \%$ concluíram os quatro primeiros anos, $14,5 \%$ não têm escolaridade e $10,3 \%$ têm curso superior completo. Pouco mais da metade $(56,8 \%)$ das mães das crianças de 0 a 6 anos que freqüentam estabelecimentos de educação trabalham.

Uma vez conhecido o perfil das crianças de 0 a 6 anos que freqüentam escola, creche ou pré-escola, procurou-se identificar como as condições socioeconômicas dessas crianças interferem na sua entrada em instituições de educação. Para isso, foram analisadas as taxas de escolarização segundo diferentes condições socioeconômicas, como se procura apresentar na seção a seguir.

\section{Fatoresque influenciam a freqüência}

\section{A idade}

A análise do grupo das crianças de 0 a 6 anos permite verificar que apenas $27,7 \%$ delas está matriculada em escola, creche ou pré-escola. Apesar desse percentual ainda ser baixo, já que corresponde a menos de um terço da demanda, pode-se constatar sua convergência com os dados apresentados no Quadro 1, que indica, como foi analisado, que a oferta vinha aumentando de
1979 a 1991. Quando, porém, as crianças são agrupadas por idade, essa proporção aumenta bastante no grupo de crianças de 4 a 6 anos, passando para 55,9\%.

\section{Gráfico 2}

Taxa de escolarização das crianças de 0 a 6 anos de idade, por grupo de idade período março 1996/março 1997

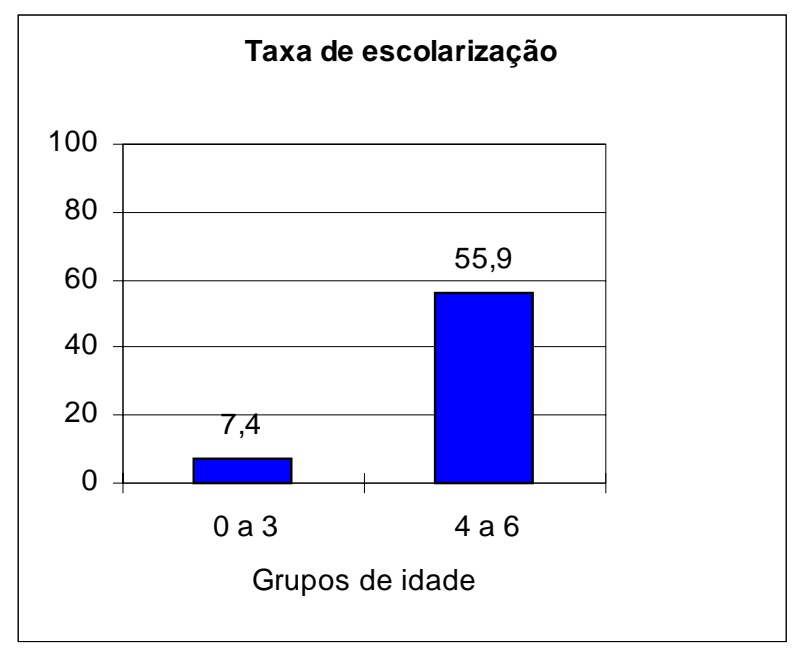

Fonte: Pesquisa sobre padrões de vida 1996-1997 [CD-ROM]. Microdados. Rio de Janeiro: IBGE, 1998.

Das crianças de 0 a 3 anos que freqüentam algum estabelecimento de educação, 54,9\% informam que estão matriculadas em creches e $45,1 \%$ em pré-escolas, sendo que $91,1 \%$ de todas essas instituições encontramse em áreas urbanas. Na verdade, como já foi comentado, a confusão em torno do nome da instituição é muito grande, tanto por parte dos pais, como das próprias instituições. No Nordeste, por exemplo, segundo os informantes, 72,9\% das crianças de 0 a 3 anos freqüentam pré-escolas e apenas $27,1 \%$ freqüentam creches. Das crianças de 4 a 6 anos, 9,5\% ainda vão à creche, $79,6 \%$ vão à pré-escola e 11,0\% freqüentam as primeiras séries do primeiro grau. Assim como as instituições que atendem às crianças de 0 a 3 anos, estas estão, na sua maioria, localizadas em zonas urbanas $(81,2 \%)$. No Sudeste, $14,4 \%$ das crianças de 4 a 6 anos ainda freqüentam creches. O Quadro 3 apresenta esta distribuição. 


\section{Q uadro 3}

Distribuição percentual de crianças de 0 a 6 anos de idade que freqüentam estabelecimentos de educação, por região de residência e situação do domicílio, segundo grupos de idade e modalidade de educação período março 1996/março 1997

\begin{tabular}{|c|c|c|c|c|c|}
\hline $\begin{array}{c}\text { Grupos de } \\
\text { idade e }\end{array}$ & \multicolumn{4}{|c|}{$\begin{array}{c}\text { Distribuição percentual de crianças de } 0 \text { a } 6 \text { anos de idade } \\
\text { que freqüentam estabelecimentos de educação (\%) }\end{array}$} \\
\cline { 3 - 6 } $\begin{array}{c}\text { Modalidade } \\
\text { de Educação }\end{array}$ & Total & \multicolumn{2}{|c|}{ Região de residência } & \multicolumn{2}{|c|}{ Situação do domićlio } \\
\cline { 3 - 6 } & & Nordeste & Sudeste & Urbana & Rural \\
\hline 0 a 3 anos & 100,0 & 42,5 & 57,5 & 91,1 & 8,9 \\
Creche & 54,9 & 27,1 & 75,4 & 53,8 & 66,5 \\
Pré-escola & 45,1 & 72,9 & 24,6 & 46,2 & 33,5 \\
& & & & & \\
4 a 6 anos & 100,0 & 47,5 & 52,5 & 81,2 & 18,8 \\
Creche & 9,5 & 4,1 & 14,4 & 10,1 & 6,9 \\
Pré-escola & 79,6 & 84,6 & 75,0 & 79,7 & 79,1 \\
1a série & 10,1 & 9,9 & 10,2 & 9,6 & 12,1 \\
2a série & 0,9 & 1,4 & 0,4 & 0,7 & 1,9 \\
& & & & & \\
\hline
\end{tabular}

Fonte: Pesquisa sobre padrões de vida 1996-1997 [CD-ROM]. Microdados. Rio de Janeiro: IBGE, 1998

Vale lembrar, entretanto, que esta informação referente ao tipo de instituição de educação infantil precisa ser relativizada, tendo em vista a ambigüidade ou imprecisão dos nomes dessas modalidades para a população em geral (a que o informante se refere quando responde se é creche ou pré-escola?).

Em relação ao turno freqüentado, é grande a diferença entre as áreas e regiões. Nas cidades, metade $(48,9 \%)$ das crianças de 0 a 3 anos vai à creche ou préescola à tarde, enquanto no campo a maioria delas $(65,8 \%)$ vai no turno da manhã. Apesar de nessa faixa etária o tempo integral ser necessário em decorrência do trabalho materno, ainda é baixo o percentual de crianças atendidas, apenas 15,8\% nas áreas urbanas e $28,3 \%$ nas áreas rurais. As crianças de 4 a 6 anos, por sua vez, freqüentam principalmente os turnos da manhã e da tarde, dividindo-se entre eles $(46,9 \%$ e $45,8 \%$, respectivamente). Na área rural, há uma ligeira predominância do turno da manhã, com 53,5\% das crianças contra 40,7\% no turno da tarde. No Nordeste, independente da faixa etária, o turno mais freqüentado é o da manhã, enquanto no Sudeste ocorre o inverso: o mais freqüentado é o da

\section{Q uadro 4}

Distribuição percentual de crianças de 0 a 6 anos de idade que freqüentam estabelecimento de educação, por região de residência e situação do domicílio, segundo grupos de idade e turno freqüentado - período março 1996/ março 1997

\begin{tabular}{|c|c|c|c|c|c|}
\hline $\begin{array}{c}\text { Grupos de } \\
\text { idade e Turno } \\
\text { freqüentado }\end{array}$ & \multicolumn{4}{|c|}{$\begin{array}{c}\text { Distribuição percentual de crianças de 0 a } 6 \text { anos de idade } \\
\text { que freqüentam estabelecimentos de educação (\%) }\end{array}$} \\
\cline { 2 - 6 } & Total & \multicolumn{2}{|c|}{ Região de residência } & \multicolumn{2}{|c|}{ Situação do domicílio } \\
\cline { 3 - 6 } & & Nordeste & Sudeste & Urbana & Rural \\
\hline 0 a 3 anos & 100,0 & 42,5 & 57,5 & 91,1 & 8,9 \\
Manhã & 38,1 & 67,6 & 16,2 & 35,4 & 65,8 \\
Tarde (1) & 45,0 & 22,2 & 61,9 & 48,9 & 5,9 \\
Integral & 16,9 & 10,2 & 21,9 & 15,8 & 28,3 \\
& & & & & \\
4 a 6 anos & 100,0 & 47,5 & 52,5 & 81,2 & 18,8 \\
Manhã & 46,9 & 59,5 & 35,4 & 45,3 & 53,5 \\
Tarde(1) & 45,8 & 35,5 & 55,1 & 47,0 & 40,7 \\
Integral & 7,3 & 2,4 & 5,0 & 7,7 & 5,8 \\
\hline
\end{tabular}

Fonte: Pesquisa sobre padrões de vida 1996-1997 [CD-ROM]. Microdados. Rio de Janeiro: IBGE, 1998.

(1)Engloba o turno vespertino.

tarde. Cabe também observar que o horário integral atende, no Sudeste, $21,9 \%$ das crianças de 0 a 3 anos, enquanto no Nordeste atende $10,2 \%$.

Aqui faltou verificar - a pergunta não foi incluída no questionário - se as famílias matriculariam as crianças em horário integral se a oferta existisse. Seria importante levantar este aspecto tão polêmico no campo das políticas públicas, pois muitas vezes se defende a necessidade de escolas de tempo integral para crianças mais velhas e no entanto se minimiza a oferta desta modalidade para as crianças de 0 a 6 anos. Considerar este aspecto em pesquisas futuras seria também fundamental.

\section{Por que não freqüentam? E com quem fica a criança?}

E por que razão, segundo os informantes, as crianças não freqüentam estabelecimentos de educação? Sobre este quesito a expectativa de análise era grande, na medida em que poderia apontar problemas em termos de falta de vagas, inexistência de escola, creche ou préescola na área de moradia, custos indiretos de material, 
ausência de transporte ou dificuldade de locomoção da criança de casa até a instituição de educação. Infelizmente, ficou inviabilizada a possibilidade de qualquer inferência, porque a grande maioria das respostas, nas duas faixas etárias, corresponde a "outros motivos", que não se encontram explicitados. No entanto, ao analisar o pequeno número das respostas disponíveis (ver gráfico a seguir), percebe-se que o motivo mais significativo das crianças não estarem matriculadas em estabelecimentos de educação é sua inexistência perto de suas casas. No caso da criança de 4 a 6 , as dificuldades financeiras representam 8,4\% (também importante).

\section{Gráfico 3}

Crianças de 0 a 6 anos de idade que não freqüentam estabelecimentos de educação por motivo de não-freqüência e grupos de idade - período março 1996/março 1997

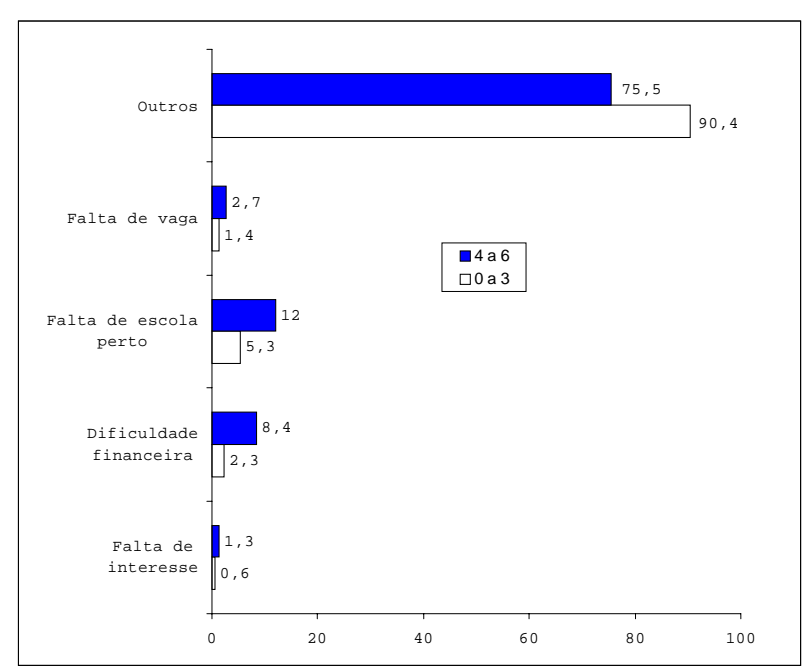

Fonte: Pesquisa sobre padrões de vida 1996-1997 [CD-ROM]. Microdados. Rio de Janeiro: IBGE, 1998.

Mas que outras razões a resposta "outros" terá encoberto? Esta é, sem dúvida, uma importante questão que merece estudos posteriores.

Entretanto, segundo os questionários, na maioria dos casos (81,3\%), a criança que não freqüenta escola, creche ou pré-escola fica com sua mãe. Como este número pareceu muito elevado, considerando-se o índice de mulheres no mercado de trabalho, foi investigada a história dessas mães. Verificou-se então que, das mães que trabalham fora de casa e que não têm o filho matriculado em estabelecimentos de educação, 58,1\% ficam em casa com os filhos, mas esse número sobe para $96,2 \%$ para as mães que não trabalham. Outras pessoas também cuidam das crianças que não freqüentam escola, creche ou pré-escola: os avós (6,6\%), os irmãos $(4,2 \%)$, outros parentes $(3,9 \%)$, outra pessoa $(1,6 \%)$, a empregada doméstica $(1,6 \%)$ e o pai $(0,8 \%)$. Apesar da baixa percentagem $(0,1 \%)$, é importante destacar que mais de 10 mil crianças das Regiões Nordeste e Sudeste aproximadamente, que não freqüentam escola, ficam em casa sozinhas, enquanto as mães trabalham foram. São crianças de 5 e 6 anos com famílias de baixa renda ( $1^{\circ}$ quinto) que moram em áreas rurais no Sudeste $(41,7 \%)$ e no Nordeste $(58,3 \%)$, cujas mães não possuem escolaridade.

Já as crianças que freqüentam algum tipo de estabelecimento de educação infantil, quando não estão na creche, pré-escola ou escola, também ficam com suas mães em 74,6\% dos casos. E essas mulheres trabalham, em média, 33 horas e 28 minutos por semana. Também ficam com as crianças matriculadas em instituições de educação, quando estão em casa: os avós (8,8\%), a empregada doméstica $(4,5 \%)$, os irmãos $(3,9 \%)$, outros parentes $(3,9 \%)$, outra pessoa $(2,5 \%)$ e o pai $(1,5 \%)$. Mas mais de 12 mil crianças do Nordeste e Sudeste que freqüentam escola, creche ou pré-escola também ficam em casa sozinhas. São crianças de 4 a 6 anos, pobres $\left(2^{\circ}\right.$ e $3^{\circ}$ quintos), que moram na zona urbana, no Nordeste $(87,9 \%)$ ou no Sudeste $(12,1 \%)$, cujas mães completaram, na sua maioria $(79,0 \%)$, o $2^{\circ}$ grau.

\section{Condições geográficas, de sexo e raciais}

Ao se levar em consideração os níveis de escolarização nas diferentes regiões e áreas, surpreende a constatação de que a diferença é muito pequena em termos de regiões geográficas. De fato, as taxas de escolarização se eqüivalem nas regiões Nordeste e Sudeste, o que pode sugerir que, no que diz respeito ao atendimento das crianças de 0 a 6 anos, a carência é a mesma. A comparação, entretanto, das taxas de escolarização das áreas urbana e rural, evidencia diferenças significativas. Nas duas faixas etárias, as taxas das áreas urbanas superam as das áreas rurais. Podem ser encontrados tam- 
bém níveis de escolarização superiores entre as crianças de 4 a 6 anos que residem em área metropolitana. Essa diferença, entretanto, desaparece no que se refere às crianças de 0 a 3 anos.

\section{Gráfico 4}

Taxas de escolarização das crianças de 0 a 6 anos de idade, por região de residência e situação do domicílio, segundo grupos de idade - período março 1996/março 1997

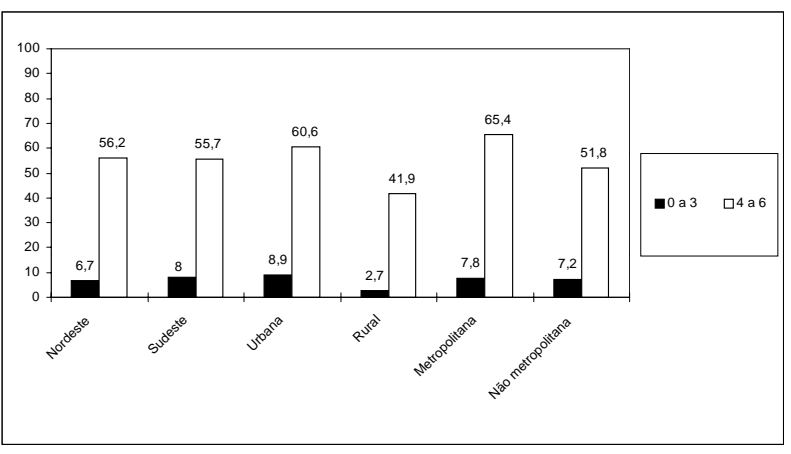

Fonte: Pesquisa sobre padrões de vida 1996-1997 [CD-ROM]. Microdados. Rio de Janeiro: IBGE, 1998.

E quem nasce menina tem mais chance de freqüentar estabelecimentos de educação antes dos seis anos? Não. As chances são as mesmas para os dois sexos, como pode ser observado no Quadro 5. O que faz realmente diferença é a cor: as taxas de escolarização das crianças brancas são significativamente maiores $(15,5$ pontos percentuais na faixa das crianças de 4 a 6 anos) do que as das crianças pretas/pardas.

\section{Q uadro 5}

Taxas de escolarização das crianças, por sexo e cor, segundo grupos de idade período março 1996/março 1997

\begin{tabular}{|c|c|c|c|c|}
\hline \multirow{3}{*}{$\begin{array}{c}\text { Grupos de } \\
\text { idade }\end{array}$} & \multicolumn{3}{|c|}{$\begin{array}{r}\text { Taxas de escolarização das crianças } \\
\text { de 0 a } 6 \text { anos de idade (\%) }\end{array}$} \\
\cline { 2 - 5 } & \multicolumn{2}{|c|}{ Sexo } & \multicolumn{2}{c|}{ Cor } \\
\cline { 2 - 5 } & meninos & meninas & branca & preta/parda \\
\hline 0 a 3 anos & 7,9 & 6,9 & 9,6 & 4,8 \\
4 a 6 anos & 55,4 & 56,4 & 63,8 & 48,3 \\
& & & & \\
\hline
\end{tabular}

Fonte: Pesquisa sobre padrões de vida 1996-1997 [CD-ROM]. Microdados. Rio de Janeiro: IBGE, 1998.

\section{Condições socioeconômicas}

Um dos fatores que mais influencia na escolaridade das crianças é, sem dúvida, a renda da família. A análise das taxas de escolarização, considerando-se os quintos de renda domiciliar per capita, permite identificar uma nítida desigualdade entre as crianças mais ricas (do $5^{\circ}$ quinto) e as mais pobres (do $1^{\circ}$ quinto): à medida que aumenta a renda familiar, crescem os níveis de escolarização.

\section{Gráfico 5}

Taxas de escolarização das crianças, por quintos de renda domiciliar per capita, segundo grupos de idade

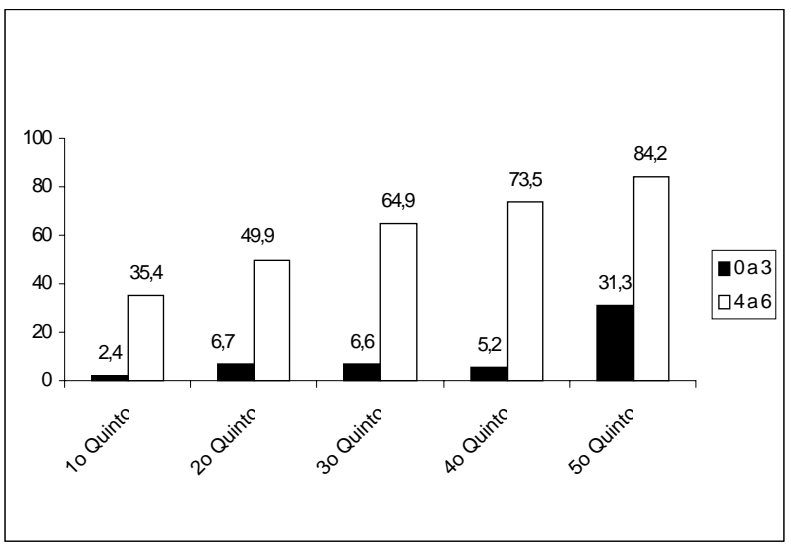

Fonte: Pesquisa sobre padrões de vida 1996-1997 [CD-ROM]. Microdados. Rio de Janeiro: IBGE, 1998.

Além de analisar a variação da taxa de escolarização em relação aos quintos de renda, pode-se também analisá-la em relação às condições de moradia: tipo de domicílio (casa ou apartamento), local (condomínio regular, favela, casa de cômodos ou cortiço, construção isolada), condição de ocupação (alugado, próprio, cedido, invadido) e condição de saneamento (tipo de iluminação, abastecimento de água e coleta de esgoto). Como as condições de moradia estão diretamente ligadas à renda familiar, os resultados tornam-se presumíveis. Assim, as crianças que moram em domicílios em melhores condições (casas ou apartamentos próprios em condomínios regularizados com luz elétrica, água encanada, fossa séptica ou rede coletora de esgoto) têm maior probabilidade de freqüentar creche, pré-escola ou escola. 
O único fato a destacar seria a alta taxa de escolarização $(91,3 \%)$ de crianças de 4 a 6 anos morando em apartamento. Creche, pré-escola ou escola, para as crianças da cidade que vivem em apartamentos, é quase um consenso. É o que pode ser observado no quadro apresentado a seguir.

\section{Quadro 6}

Taxas de escolarização das crianças de 0 a 6 anos de idade, por tipo de domicílio e condição de ocupação, segundo grupos de idade - período março 1996 /março 1997

\begin{tabular}{|c|c|c|c|c|c|c|}
\hline \multirow{2}{*}{$\begin{array}{c}\text { Grupo } \\
\text { s De } \\
\text { idade }\end{array}$} & \multicolumn{3}{|c|}{ Taxas de escolarização das crianças de 0 a 6 anos de idade (\%) } \\
\cline { 2 - 7 } & Tipo de domicílio & \multicolumn{4}{|c|}{ Condição de ocupação } \\
\cline { 2 - 7 } & Casa & Apartamento & Alugado & Próprio & Cedido & Invadido \\
\hline 0 A 3 & 7,0 & 15,6 & 10,5 & 7,7 & 4,9 & 0,6 \\
\hline & & & & & & \\
\hline 4 a 6 & 53,8 & 91,3 & 61,6 & 57,1 & 51,9 & 27,1 \\
\hline
\end{tabular}

Fonte: Pesquisa sobre padrões de vida 1996-1997 [CD-ROM]. Microdados. Rio de Janeiro: IBGE, 1998.

\section{Condições familiares}

Outros fatores que podem interferir na taxa de escolarização das crianças são aqueles que dizem respeito à estrutura familiar: número de pessoas que moram com a criança, sua condição na casa (filho, outro parente ou agregado), o grau de escolaridade de seus pais, tempo de trabalho de sua mãe. Observando o Quadro 7 , que apresenta a taxa de escolarização por número de pessoas no domicílio, percebe-se que quanto maior a família, menor a probabilidade da criança frequientar a creche, pré-escola ou escola.

Contudo, ao analisar como a condição na unidade domiciliar interfere na entrada das crianças em estabelecimentos de educação, percebe-se que os agregados da família têm maior chance de entrar na creche, préescola ou escola até os seis anos do que os filhos ou outros parentes, chegando a $100 \%$ no grupo etário que abrange as crianças de 4 a 6 anos. Isso provavelmente se deve ao fato desses agregados serem filhos de empregados que, portanto, seriam matriculados em alguma modalidade de educação infantil a fim de liberar os pais para o trabalho. Entretanto, deve-se ressaltar que o número de agregados na amostra é muito pequeno, o que torna estes resultados pouco confiáveis.

\section{Q uadro 7}

Taxa de escolarização das crianças de 0 a 6 anos de idade, por número de pessoas no domicílio, segundo grupos de idade período março 1996/março 1997

\begin{tabular}{|c|c|c|c|c|}
\hline \multirow{3}{*}{$\begin{array}{c}\text { Grupos de } \\
\text { idade }\end{array}$} & \multicolumn{4}{|c|}{$\begin{array}{c}\text { Taxas de escolarização das crianças } \\
\text { de } 0 \text { a } 6 \text { anos de idade (\%) }\end{array}$} \\
\cline { 2 - 5 } & \multicolumn{4}{|c|}{ Número de pessoas no domicílio } \\
\cline { 2 - 5 } & 2 a 4 & 5 a 6 & 7 a 10 & Mais de 10 \\
\hline 0 a 3 anos & 10,6 & 4,7 & 3,5 & 2,7 \\
4 a 6 anos & 61,2 & 60,3 & 41,9 & 34,3 \\
& & & & \\
\hline
\end{tabular}

Fonte: Pesquisa sobre padrões de vida 1996-1997 [CD-ROM]. Microdados. Rio de Janeiro: IBGE, 1998.

\section{Q uadro 8}

Taxas de escolarização das crianças de 0 a 6 anos de idade, por condição na unidade domiciliar, segundo grupos de idade

\begin{tabular}{|c|c|c|c|}
\hline \multirow{2}{*}{$\begin{array}{c}\text { Grupos de } \\
\text { idade }\end{array}$} & \multicolumn{3}{|c|}{$\begin{array}{c}\text { Taxas de escolarização das crianças } \\
\text { de } 0 \text { a } 6 \text { anos de idade (\%) }\end{array}$} \\
\cline { 2 - 4 } & \multicolumn{3}{|c|}{ Condição na unidade domiciliar } \\
\cline { 2 - 4 } & Filho & Outro parente & Agregado \\
\hline 0 a 3 anos & 7,8 & 5,6 & 10,3 \\
4 a 6 anos & 56,9 & 49,4 & 100,0 \\
\hline
\end{tabular}

Fonte: Pesquisa sobre padrões de vida 1996-1997 [CD-ROM]. Microdados. Rio de Janeiro: IBGE, 1998.

Porém, o que mais causa impacto na escolaridade das crianças é a escolaridade de seus pais, principalmente da mãe. Pode-se observar que a probabilidade das crianças estarem na creche, pré-escola ou escola aumenta conforme aumenta o grau de escolaridade de seus pais, chegando a $100 \%$ para as mães com mestrado ou doutorado, nas duas faixas etárias. Vale refletir aqui sobre o seguinte aspecto: mais do que determinar ou predizer o grau de escolaridade futuro, a freqüência à creche ou pré-escola e a escolaridade mais alta é que resultam de um conjunto de fatores de ordem socioeconômica, cultural e familiar. Assim, é o contexto em que estão inseridas as crianças e seus condicionantes que favore- 
cem começar antes e estudar até mais tarde, ou seja, ter acesso à Educação Infantil e a níveis de escolaridade mais elevados.

\section{Gráfico 6}

Taxas de escolarização das crianças de

0 a 6 anos de idade, por escolaridade do pai e da mãe, segundo grupos de idade período março 1996/março 1997

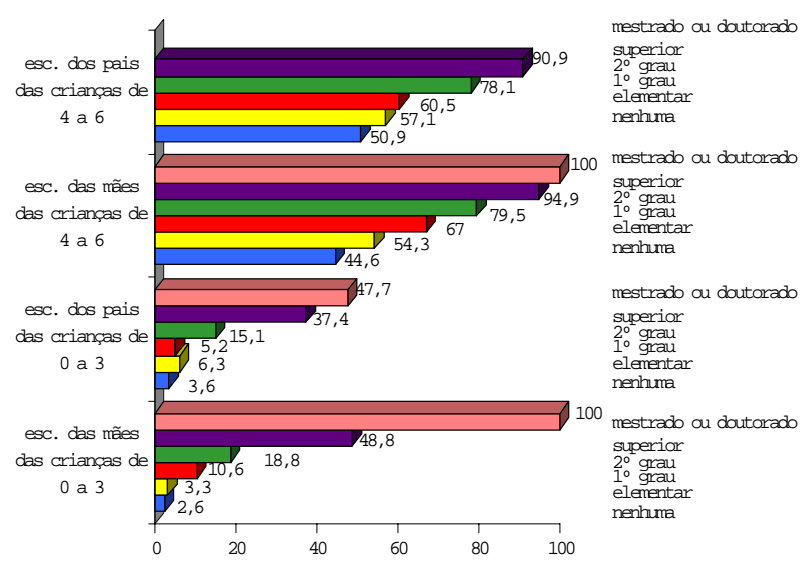

Fonte: Pesquisa sobre padrões de vida 1996-1997 [CD-ROM]. Microdados. Rio de Janeiro: IBGE, 1998.

E se a mãe trabalha, aumentam as probabilidades da criança freqüentar estabelecimentos de educação? As crianças de 0 a 3 anos cujas mães trabalham têm 3,8 vezes as chances de frequientar a creche ou pré-escola daquelas cujas mães não trabalham (a taxa de escolarização é de $14,9 \%$ e 3,9\%, respectivamente). As crianças de 4 a 6 anos cujas mães trabalham também vão mais à creche, pré-escola ou escola, em relação àquelas cujas mães não trabalham $(59,8 \%$ e $51,6 \%$, respectivamente).

\section{O trabalho infantil}

$\mathrm{Na}$ época em que foi feita a pesquisa, $0,5 \%$ das crianças com 5 e 6 anos $^{6}$ trabalhavam e $0,6 \%$ responde-

${ }^{6}$ A seção da Pesquisa sobre Padrões de Vida sobre trabalho só foi respondida por pessoas com mais de 5 anos. ram que já tinham alguma vez trabalhado. Destes, $34,2 \%$ começaram a trabalhar com 5 anos e 65,8\% com 6 anos, todos como ajudantes não remunerados em atividades agropecuárias realizadas em sítios ou fazendas. Apesar desses percentuais serem baixos, é preciso observar que se trata de 15.800 crianças de baixa renda ( $1^{\circ}$ quinto) de 5 e 6 anos, trabalhando, no Nordeste rural $(86,9 \%)$ e no Sudeste rural $(13,1 \%)$,sem qualquer tipo de remuneração, em atividades para as quais elas não têm sequer condição física. Entretanto, a maior parte das crianças que trabalham, também estudam. Apenas $0,1 \%$ do total das crianças trabalham e não estudam. $O$ trabalho infantil, portanto, não está correlacionado negativamente com a taxa de escolarização das crianças de 5 a 6 anos. A denúncia quanto à exploração do trabalho infantil situa-se aqui, portanto, como um problema do campo dos direitos da infância (todas as crianças têm o direito de não trabalhar, de freqüentar escola, creche e pré-escola, de brincar) e não por ser o trabalho um obstáculo à freqüência à escola.

\section{Gráfico 7}

Distribuição proporcional das crianças de 5 e 6 anos de idade, por condição de estudo e trabalho - período março 1996/março 1997

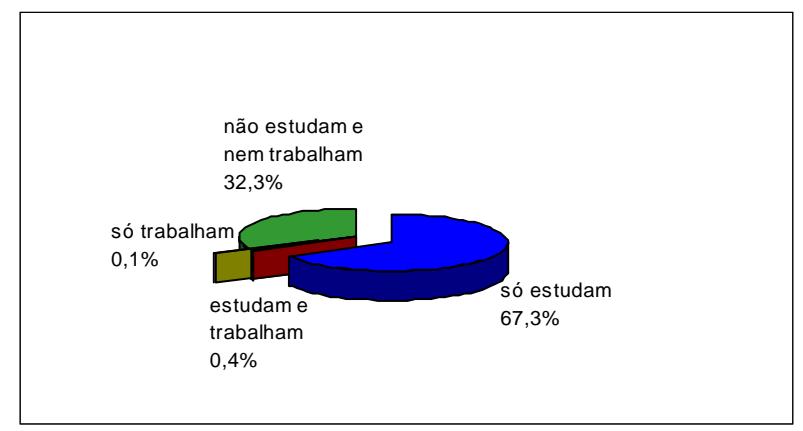

Fonte: Pesquisa sobre padrões de vida 1996-1997 [CD-ROM]. Microdados. Rio de Janeiro: IBGE, 1998.

Além disso, as ocupações com serviços ligados à casa também ocupam parte do tempo das crianças, apesar de não serem consideradas como trabalho, por não serem remuneradas. Na verdade, $12,9 \%$ das crianças ajudam suas mães em tarefas de casa, sendo que $62,0 \%$ delas encontram-se em área urbana e 51,9\% na região 
Nordeste. Mas felizmente a quase totalidade $(95,7 \%)$ das crianças de 0 a 6 anos que estão na creche, préescola ou escola brincam no horário extra-escolar. ${ }^{7}$ Este é um aspecto fundamental, tendo-se em vista a importância da brincadeira para o desenvolvimento da criança, a aprendizagem e a constituição de sua subjetividade. Além de brincar, as crianças vêem televisão (79,5\%), estudam $(48,9 \%)$, fazem esportes $(4,2 \%)$ e freqüentam cursos $(2,3 \%)$. É pena que não tenham sido levantadas com a PPV - também as atividades realizadas pelas crianças que não estão matriculadas em creches, préescolas ou escolas, e esta continua sendo uma necessidade em termos de pesquisas futuras.

\section{Consideraçõesfinaise recomendações}

Este trabalho apresentou e discutiu dados da Pesquisa Padrões de Vida/PPV, realizada pelo IBGE, específicos à educação da criança de 0 a 6 anos. Procurou-se identificar quem são as crianças de 0 a 6 anos que freqüentam creches, pré-escolas e escolas nas regiões Nordeste e Sudeste e os fatores que influenciam esta freqüência. A título de considerações finais, vale insistir na necessidade de realizar pesquisas contemplando as dimensões quantitativa e qualitativa, de modo a viabilizar o delineamento do perfil das populações infantis de 0 a 6 anos. Caracterizar estas populações, conhecer o que fazem as crianças, de que brincam, em que e como trabalham, se estudam, entre outras informações, é tarefa fundamental.

É consenso que a educação de crianças pequenas é uma das áreas educacionais que mais retribuem à sociedade os recursos que foram nela investidos. Os dados permitem corroborar este posicionamento e afirmar a urgente expansão da oferta de creches e pré-escolas, de modo a assegurar que o preceito constitucional se torne fato, garantindo acesso a todas as crianças à educação infantil de qualidade, que contribuam efetivamente para o desenvolvimento e o conhecimento das crianças.

${ }^{7} \mathrm{O}$ questionário só apresentava esses dados para as crianças matriculadas.
$\mathrm{Na}$ PPV, foi encontrada uma taxa de escolarização que se aproxima bastante dos índices nacionais, ${ }^{8}$ em termos do atendimento aos grupos de 0 a 3 anos e de 4 a 6 anos. $O$ fator idade se mostrou bastante forte no acesso das crianças à educação: mais da metade das crianças de crianças de 4 a 6 anos estava matriculada em creche, pré-escola ou escola, e menos de $10,0 \%$ das de 0 a 3 anos. O quesito renda revelou-se igualmente muito importante: quanto maior a renda, maior a freqüência à creches, pré-escolas ou escolas, o que significa que este é ainda um serviço que beneficia mais as famílias de nível socioeconômico mais elevado. Já no que se refere à cor, o acesso de crianças brancas à educação infantil mostrou-se maior que o de pretas/pardas, o que configura um contexto onde a discriminação está presente, confirmando resultados de outras pesquisas realizadas. Também foi visível o peso que joga a escolaridade da mãe na freqüência das crianças de 0 a 6 anos a estabelecimentos de educação, tendência já identificada por outros estudos.

Um ponto positivo observado relaciona-se à proporção de crianças matriculadas na rede pública, sendo mais elevada esta proporção na zona rural. Cabe lembrar que o avanço da oferta de vagas na rede pública é uma tendência que vem se afirmando na última década, e que foi constatada também na revisão dos dados feita em perspectiva histórica.

Os dados sugerem ainda que quase a totalidade das crianças brincam, aspecto fundamental, mas não foi possível identificar de que as crianças brincam. Além de brincar, a maioria vê televisão, estuda e pratica esportes. Ainda quanto às atividades infantis, preocupa muito o fato de terem sido encontradas crianças de 5 e 6 anos que trabalham e, além disso - o que torna mais grave o que já é grave - sem remuneração. É pena que não tenham sido levantadas, pela PPV, também as atividades realizadas pelas crianças que não estão matriculadas em creches e pré-escolas, o que continua sendo uma necessidade em termos de pesquisas futuras.

Como limites da pesquisa realizada, cabe indagar até que ponto a forma de aplicação do questionário pode

${ }^{8}$ Resultados da Pesquisa Nacional por Amostra de Domicílios, 1997 
ter condicionado ou influenciado os resultados obtidos, no caso de certos quesitos. É bem verdade que em pesquisas deste tipo, baseadas nas informação fornecidas, muitas respostas podem não corresponder à realidade.

$\mathrm{O}$ aperfeiçoamento dos instrumentos de coleta e a maior clareza de dados e análises exigem outras pesquisas com tal abrangência, no bojo de políticas públicas comprometidas com o direito à educação de todas as crianças, neste caso as de 0 a 6 anos de idade.

MARIA CRISTINA CARVALHO é doutoranda em educação da PUC-Rio. Juntamente, com Sonia Kramer, Maria Isabel Leite e Eliane Fazolo, organizou Educação infantil em curso (1997), no qual assina o capítulo "Infância, leitura e escrita: entrando com Vygotsky numa escola de formação de professores". Apresentou os trabalhos "Lugares da leitura e da escrita numa escola de formação", na 23a. Reunião Anual da Anped. (Rio de Janeiro, Anped, 2000, Anais, p. 100) e "O campo de investigação: falando das escolas", no $X$ ENDIPE (Ensinar e aprender: sujeitos, saberes, espaços e tempos. Anais. Rio de Janeiro, Endipe, p.168, maio de 2000). E-mail: ccarvalho@openlink.com.br

MARIA DOLORES BOMBARDELLI KAPPELé mestre em educação pela PUC-Rio e pesquisadora titular do Instituto Brasileiro de Geografia e Estatística, Departamento de População e Indicadores Sociais - IBGE/DEPIS. Publicou: "Educação fundamental: o censo domiciliar de 1996 como parâmetro para o Plano Nacional de Educação 1998-2007”, em co-autoria com José Carmelo Braz de Carvalho (ANPEd, 21 ${ }^{a}$. Reunião Anual, Anais. Rio de Janeiro, Anped, 1998); “Educação", em Pesquisa sobre Padrões de Vida 1996-1997 (IBGE/ Banco Mundial, Rio de Janeiro, 1999); “As crianças de 0 a 6 anos nas estatísticas nacionais", apresentado no Seminário Internacional da OMEP - Organização Mundial para Educação Pré-escolar (2000); "Perfil da Educação", no Atlas Nacional do Brasil (Rio de Janeiro, IBGE, dez. 2000); capítulo "Educação", em Síntese dos Indicadores Sociais - 2000 (Rio de Janeiro, IBGE, 2001, Estudos e Pesquisas - Informações Demográficas e Socioeconômicas, nº 4).

SONIA KRAMER é doutora em educação pela PUC-Rio e professora do Departamento de Educação dessa Universidade. $\mathrm{Pu}$ blicou: Por entre as pedras: arma e sonho na escola (1994); Alfabetização, leitura e escrita: formação de professores em curso (1995); Histórias de professores (1996, organizado juntamente com Solange Jobim e Souza); Infância: fios e desafios da pesquisa. (1996, organizado juntamente com Maria Isabel Leite). E-mail: sokramer@edu.puc-rio.br

\section{Referências Bibliográficas}

BRASIL. MEC. Coordenação de Educação Pré-Escolar, (1975). Diagnóstico Preliminar da Educação Pré-Escolar no Brasil. Brasília, MEC/DDD.

BRASIL. IBGE. Censo Demográfico 1980, (1983). Dados gerais, migração, instrução, fecundidade, mortalidade. Brasil. Rio de Janeiro: IBGE, v.1, t.4, n.1.

1991, Características gerais da população e instrução. Brasil. Rio de Janeiro: IBGE, 1996, n.1.

Pesquisa sobre padrões de vida, 1996/7. Microdados

BRASIL. IBGE, (1998). Pesquisa sobre padrões de vida 1996-1997 [CD-ROM]. Microdados. Rio de Janeiro: IBGE.

CAMPOS, Maria Malta, (1986). “A Constituinte e a educação da criança de 0 a 6 anos". Cadernos de Pesquisa, São Paulo: Fundação Carlos Chagas, n. 59, p. 57-65, nov.

(1997). "Educação infantil: o debate e a pesquisa". Cadernos de Pesquisa. São Paulo: Fundação Carlos Chagas, n. 101, p. 113-127, jul.

FERRARI, Alceu R., GASPARY, Lúcia Beatriz Velloso, (1980). Distribuição das oportunidades de educação pré-escolar no Brasil. Educação e Sociedade. São Paulo: Cortez \& Autores Associados, n.5, p. 62-79, jan.

KRAMER, Sonia, (1988). “Criança e legislação - a educação de 0 a 6 anos". Em Aberto. Brasília: INEP/MEC, ano 7, n. 38, p. 33-38, abril/ junho.

(1992). A política do pré-escolar no Brasil: a arte do disfarce. São Paulo: Cortez.

POZNER, Pilar, (1982). El impacto del pre-escolar en los niños de sectores populares. Cadernos de Pesquisa, São Paulo: Fundação Carlos Chagas, n. 42, p. 63-78, ago. 1982,

ROSEMBERG, Fúlvia, (1996). "Educação infantil, classe, raça e gênero". Cadernos de Pesquisa, São Paulo: Fundação Carlos Chagas, n. 96, p. 58-65, fev.

(1999). “O estado dos dados para avaliar políticas de educação infantil". Estudos em Avaliação educacional. São Paulo, Fundação Carlos Chagas, nº 20, jul.-dez. 